\title{
Experimental and numerical investigation of thermal energy storage with a finned tube
}

\author{
Aytunç Erek ${ }^{1, *, \dagger}$, Zafer İlken ${ }^{2}$ and Mehmet Ali Acar ${ }^{1}$ \\ ${ }^{1}$ Department of Mechanical Engineering, Dokuz Eylül University, Bornova, 35100, İzmir, Turkey \\ ${ }^{2}$ Department of Mechanical Engineering, İmir Institute of Technology, Urla, 35430, Izmir, Turkey
}

\begin{abstract}
SUMMARY
A latent heat thermal energy storage system using a phase change material (PCM) is an efficient way of storing or releasing a large amount of heat during melting or solidification. It has been determined that the shell-and-tube type heat exchanger is the most promising device as a latent heat system that requires high efficiency for a minimum volume. In this type of heat exchanger, the PCM fills the annular shell space around the finned tube while the heat transfer fluid flows within the tube.

One of the methods used for increasing the rate of energy storage is to increase the heat transfer surface area by employing finned surfaces. In this study, energy storage by phase change around a radially finned tube is investigated numerically and experimentally. The solution of the system consists of the solving governing equations for the heat transfer fluid (HTF), pipe wall and phase change material. Numerical simulations are performed to investigate the effect of several fin parameters (fin spacing and fin diameter) and flow parameter (Re number and inlet temperature of HTF) and compare with experimental results. The effect of each variable on energy storage and amount of solidification are presented graphically. Copyright (C) 2005 John Wiley \& Sons, Ltd.
\end{abstract}

KEY WORDS: finned tube; phase change; solidification; thermal energy storage

\section{INTRODUCTION}

Cooling of buildings in many countries, especially in the United States, is a major factor to the peak electrical load. To decrease this peak load, off-peak electricity during night is stored as cold energy storage by producing cold water or ice to be utilized by the cooling system in the day time.

Due to the narrow band of temperature variation for the phase-change material and low volume requirements per unit energy stored, storing energy through a phase-change phenomenon has been a focus of researchers. Numerous studies related to the heat transfer through melting or solidification has been published in the last decade. A detailed review about latent energy storage system is provided by Eckert et al. (1997), by Zalba et al. (2003), by Saito

\footnotetext{
*Correspondence to: Aytunç Erek, Department of Mechanical Engineering, Dokuz Eylül University, Bornova, 35100 , İzmir, Turkey.

${ }^{\dagger}$ E-mail: aytunc.erek@deu.edu.tr

Contract/grant sponsor: Natural Science Foundation; contract/grant number: 02.KB.FEN.028
}

Copyright (C) 2005 John Wiley \& Sons, Ltd.

Received 13 January 2004 Accepted 30 April 2004 
(2002) and by Dinçer and Rosen (2002). Saito explained the concept of the cold thermal energy storage and defined their types. On the other hand, three aspects were focused widely on Zalba et al.'s study: materials, heat transfer and applications.

In designing a latent heat storage unit, the melting or solidification periods of a certain phase material has to be known. In addition, to predict the heat transfer coefficients during the phase change process, one must know the operating conditions and the storage configuration. Referring to literature, two types of configurations have been essentially studied. One of them is the shell-and-tube-type heat exchanger with the phase change material placed in the shell, and the heat transfer fluid flowing through the tubes. Studies related to this configuration are done by Ismail and Alves (1986), Cao and Faghri (1991a), Cao and Faghri (1991b), Zhang and Faghri (1996a), Bellecci and Conti (1993), and Lacroix (1993). The second configuration is a rigid capsule in which the phase change material has been placed, and the heat transfer material flows through a tube surrounding the capsule. It has been determined that the shell-and-tube type heat exchanger is the most promising device as a latent heat storage system that requires high efficiency for a minimum volume. As described previously, in such an energy storing unit, the phase change material (PCM) fills the shell and the heat transfer fluid (HTF) flowing through the tubes, serves to convey the stored energy to and from the unit. Recently, a theoretical model of the shell-and-tube type unit for storing energy has been reported by Ismail and Alves (1986). In addition, Cao and Faghri (1991b, 1992) also modelled a similar problem at which both the heat charging and the recovery processes were performed by the circulating fluid. For both models, the shell wall of the unit was assumed to be adiabatic. Using the enthalpy model, the problem of storing energy in a shell-and-tube type unit was also solved by Bellecci and Conti (1993). Cao and Faghri (1991a) studied the latent heat energy storage systems for both annular and countercurrent flows and numerically determined that the storage system with the countercurrent flow was an efficient way to absorb heat energy.

One of the methods used for increasing the rate of energy storage is to increase the heat transfer surface area by employing finned surfaces. To investigate the effect of fins with rectangular cross-section on the rate of melting and solidification, numerous studies both experimental and theoretical have been published. Bathelt and Viskanta (1981) studied the solidification problem around a horizontal finned tube with four different fin spacings were presented by Sasaguchi et al. (1989). Situating the finned tube vertically, Sparrow et al. (1981) experimentally investigated the shapes of the frozen layer on tubes with four fins. Solidification within two concentric cylinders having longitudinal fins was theoretically studied by Padmanabhan and Khrishna (1989) and a correlation relating the percent of solidification to the fin thickness and length, the number of fins, the Stefan and the Fourier numbers of the problem were stated. On the other hand, Sasaguchi and Sakamato (1989) theoretically studied the melting phenomena on the same geometry by considering strong influence of natural convection on melting. A theoretical model for predicting the transient behaviour of a shell-andtube storage unit with the PCM on the shell side and HTF circulating through the finned tube or bare tube was presented by Lacroix (1993). The effect of the wall and fin thicknesses on thermal energy storage is neglected. Zhang and Faghri (1996b) indicated that heat transfer in the latent heat thermal energy storing system might be enhanced by using internally finned tubes. Ismail et al. (2000) presents a numerical model for the solidification of phase change material around a radially finned tube with a constant inner wall temperature of tube. In their study, numerical experiments were performed to investigate the effects of the number of fins, fin thickness, fin material, aspect ratio of tube arrangement and the tube wall temperature. In addition, Erek 
(1999) numerically and experimentally studied the solidification around the finned tube by considering fully developed velocity profile in tube.

In this study, two-dimensional phase change phenomena around a horizontal radially finned tube have been investigated numerically and an experimental test setup has been designed and built to demonstrate how accurately the numerical model predicts the thermal behaviour of the energy storage unit equipped with a finned tube. Besides the flow rate and the inlet temperature of HTF, seven finned tubes, including a bare tube, having different fin length and spacing are tested in experiments. The important objective of this study is to obtain a numerical code for predicting the thermal behaviour of energy stored system with a finned tube and compare the numerical result with experimental study.

\section{EXPERIMENTAL APPARATUS}

An experimental energy storage unit as shown schematically in Figure 1 was constructed and experiments were performed. Experimental unit consists of the flow system, heat transfer test section and temperature measurement system.

The heat transfer test section is composed of an energy storage tank having dimensions of $420 \mathrm{~mm} \times 500 \mathrm{~mm} \times 570 \mathrm{~mm}$ (width $\times$ length $\times$ height), finned tube and phase change material around this tube. To take the photograph of the solidification fronts around the finned tube, the

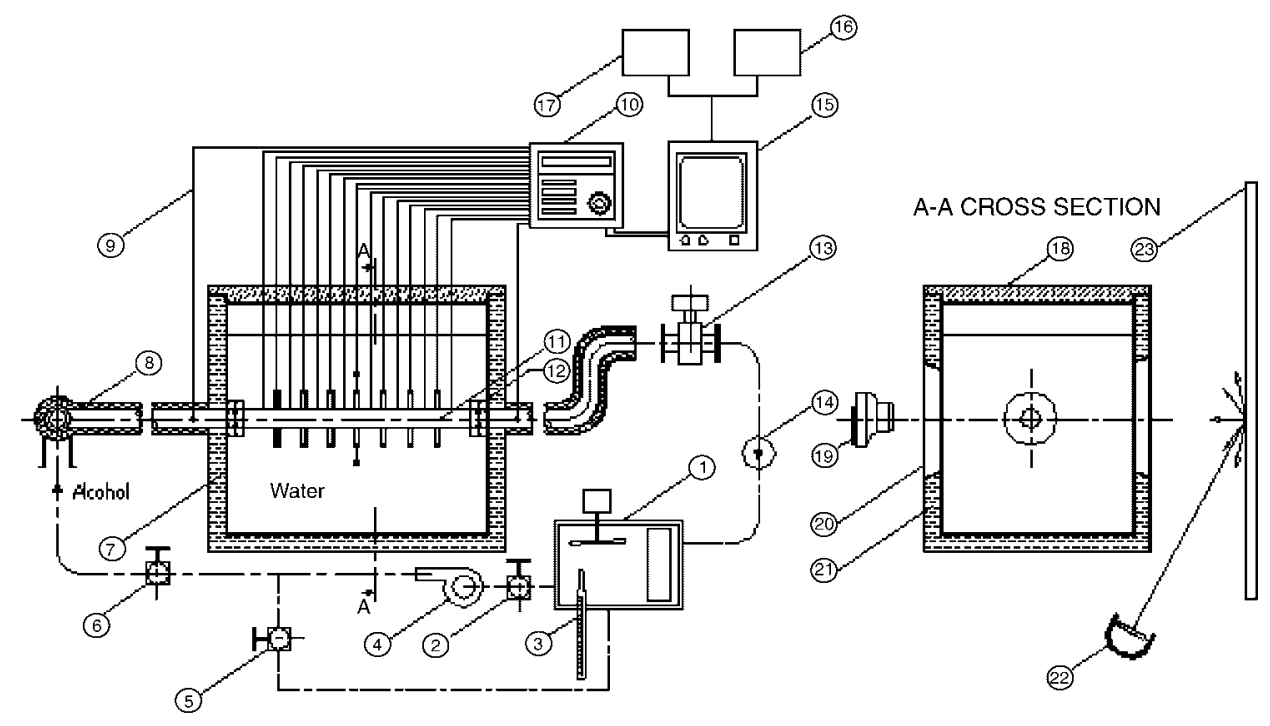

1: Constant temperature bath ; 2 : main valve; 3 : thermometer; 4 : alcohol circulation pump;

5: recirculation valve; 6 : flow adjustment valve; 7 : energy storage tank; 8 : connecting pipe; 9: thermocouple extension wires; 10: data logger, 11: finned tube; 12: fittings; 13: flow meter; 14: check valve; 15: PC computer; 16:monitor: 17: disc drive; 18: tank top cover; 19: digital camera; 20: plexiglass view window; 21 : insulation; 22 :light source; 23 : white screen

Figure 1. Experimental test unit. 
front and the back faces of the test unit were built from $10 \mathrm{~mm}$ thick Plexiglas. To reduce the heat transfer through the walls of the storage tank, the base of the tank is supported with $50 \mathrm{~mm}$ thick Styrofoam layer. The side walls and the top wall are covered with $3 \mathrm{~cm}$ thick Styrofoam layer. The finned tubes were a one-piece unit and was produced by machining a solid bronze $(87.2 \% \mathrm{Cu}, 6.57 \% \mathrm{Sn}, 4.13 \% \mathrm{Zn}$ and $1.97 \% \mathrm{~Pb})$ cylinder. Table I displays the dimensions of the finned tubes used in the experiments. All finned tubes had the same length of $480 \mathrm{~mm}$, the same fin thickness of $3 \mathrm{~mm}$, and the same inner and outer tube radius of 10 and $15 \mathrm{~mm}$, respectively.

A reservoir for the heat transfer fluid, constant temperature circulating bath, variable speed pump, flow meter and the hydrodynamic entry section are parts of constructing the flow system. The hydrodynamic entry section length is chosen long enough ( $\sim 240$ diameter, $6500 \mathrm{~mm})$ to provide fully developed flow conditions for the heat transfer fluid at the inlet of the energy storage unit. Ethyl-alcohol $\left(\mathrm{CH}_{3}-\mathrm{CH}_{2} \mathrm{OH}\right)$ is used as the heat transfer fluid to assure liquid behaviour at such a low temperature range. A Haake brand $\mathrm{T}$ model constant temperature bath is used in providing the desired temperature to alcohol at the inlet of the test section (Figure 2).

The temperature measuring system consists of temperature sensing elements (thermocouples) and data logger system. The thermocouples are embedded into midsections of the fin tip and the base sensed the surface temperature. The number of thermocouples measuring surface temperature may increase to 32 depending upon the number of fins. As displayed in Figure 1 , two thermocouples measure the inlet and outlet temperatures of the heat transfer fluid. In addition to this, two thermocouples are used for detecting the variation of the water temperature in the tank, while two thermocouples measure the ambient and the constant temperature bath. All thermocouples used in the experiments are type T of gage no. 24 and are calibrated by a constant temperature bath filled with Ethyl-alcohol. The calibration curves for each thermocouple are obtained for a temperature range between -10 and $10^{\circ} \mathrm{C}$. A HP type $34970 \mathrm{~A}$ data logger that has an accuracy of $\pm 0.04 \%$ of the reading measured the milivolt outputs of thermocouples and the measured voltage is converted into temperature automatically and transmitted to PC.

To initiate a particular set of experiments, first the finned tube at a specified type is fastened to the energy storage tank and becomes a part of the loop of the heat transfer fluid. The pure water used as the PCM preliminarily cooled down to the temperature of $0.3^{\circ} \mathrm{C}$ is pumped into the insulated storage tank. The total amount of water stored in the tank is 1101 and at a level such that the finned tube becomes oriented at the horizontal symmetry line of the tank. At this particular fin geometry, three different inlet temperatures of $-10,-15$ and $-20^{\circ} \mathrm{C}$ and six

Table I. Finned tube geometry.

\begin{tabular}{lccc}
\hline Tube type & Number of fins, $n$ & Fin diameter $(\mathrm{mm})$ & Fin spaces $(\mathrm{mm})$ \\
\hline 1 & 7 & 54 & 65 \\
2 & 7 & 64 & 65 \\
3 & 11 & 54 & 40 \\
4 & 11 & 64 & 40 \\
5 & 15 & 54 & 27.5 \\
6 & 15 & 64 & 27.5 \\
7 (bare tube) & - & - & - \\
\hline
\end{tabular}




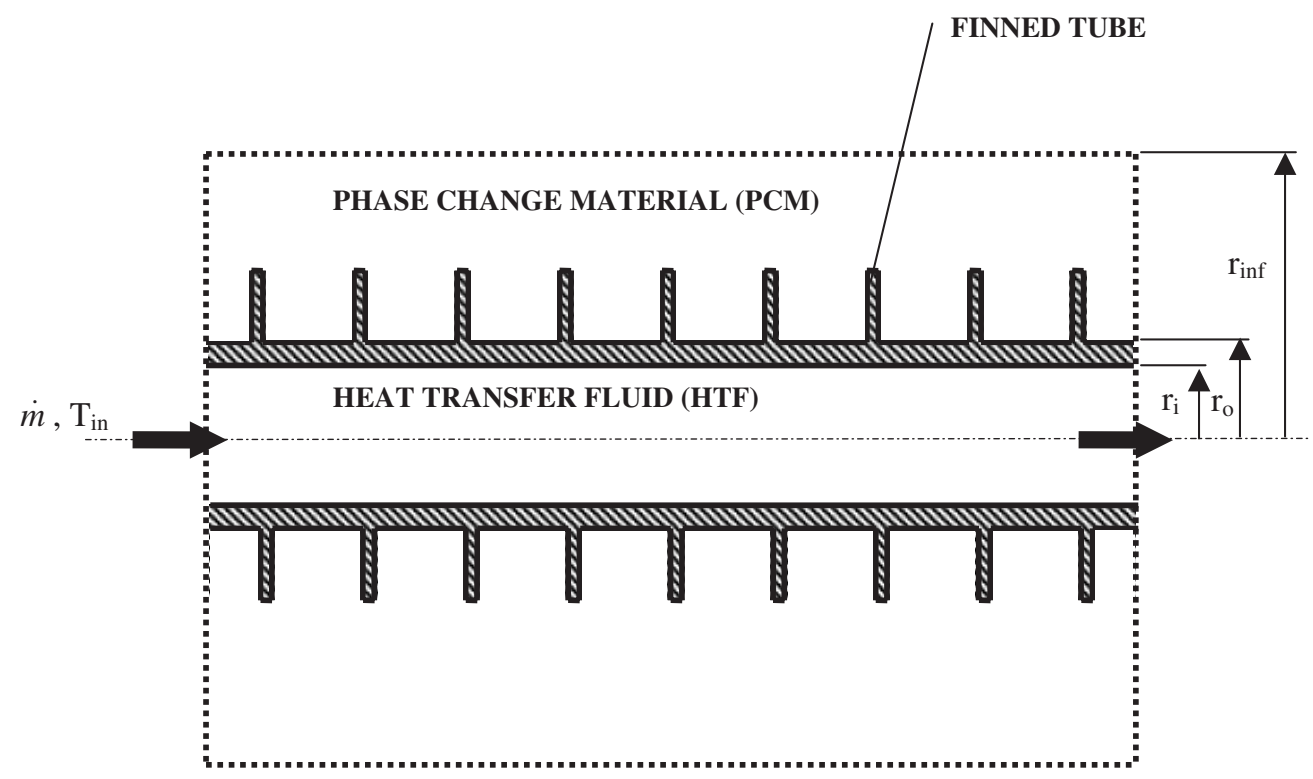

Figure 2. A schematic of the thermal energy storage system with finned tube.

different flow rates are studied. The flow rates are chosen so that Re number varies between 500 and 7000 . Thus, a total of 45 experimental runs are carried out.

The Styrofoam layers covering the Plexiglas surfaces have $25 \mathrm{~cm} \times 18 \mathrm{~cm}$ openings. To take the images of solidification phenomena at the mid-section of the finned tube and at a particular instant, these openings are used as access holes for the digital camera and light source necessary for getting a clear photography. The images of solidification are taken at every $30 \mathrm{~min}$ periods during the experiments. The images of solidification are presented in Figure 3 for the inlet temperature at $-10^{\circ} \mathrm{C}$, Re number at 500 and finned tube type 3 .

The digital camera takes the 24-bit colour images of ice formation at the size of $1280 \times 1024$ pixels and transmits to the PC through a RS232 interface. After applying special filtering techniques, bright images that clearly indicate the boundaries of the ice formed around the finned tube are obtained. Considering the scaling factor between the tube radius of these images and actual radius, the solidification radius at the axial point are measured. Thus, the volume of ice accumulated around the finned tube is calculated as

$$
V_{\text {ice,cell }}=\sum_{i=i_{1}}^{i=i_{2}} \pi .\left(r_{\text {ice }}^{2}(t)\right)_{i} . \delta x_{i}-V_{\text {finned tube,cell }}
$$

where $r_{\text {ice }}(t)$ is the ice radius at axial location $x_{i}$ on the finned tube, $\delta x_{i}$ is the axial increment and $i_{1}$ and $i_{2}$ are the mid-line between left and right fins. In order to compare with the numerical results satisfactorily, axial increment is taken as the grid size of $0.5 \mathrm{~mm}$. Total ice volume for unit tube length, $V_{\text {ice }}^{\prime}$, is calculated by linear extrapolation. For a particular flow condition and geometry, the latent heat part of total energy stored is computed as

$$
Q_{\mathrm{lat}}^{\prime}(t)=\rho \cdot V_{\mathrm{ice}}^{\prime} \cdot \Delta H
$$



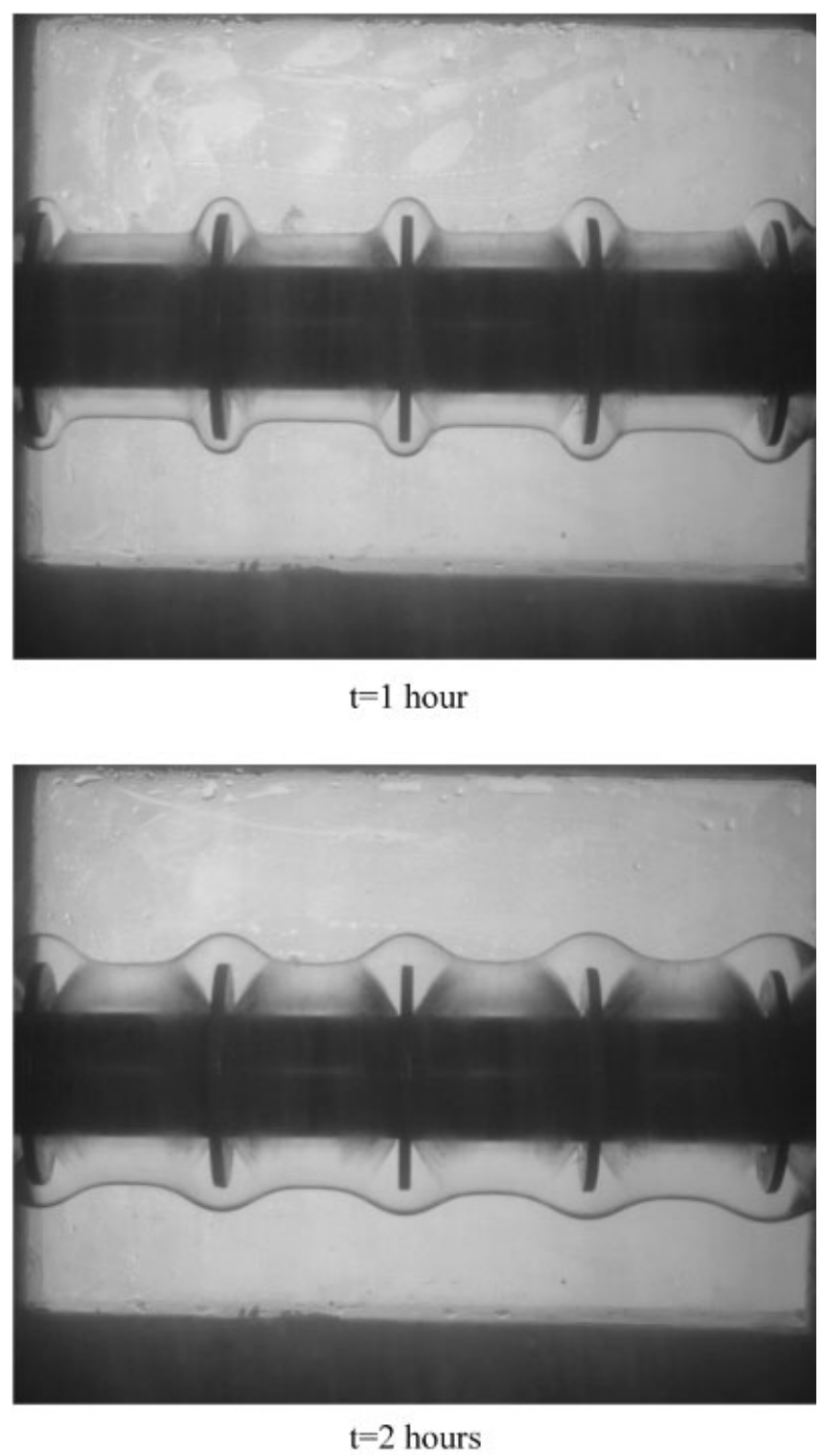

Figure 3. The solidification of finned tube type 3 at different times for inlet temperature of $\mathrm{HTF}$ of $-10^{\circ} \mathrm{C}$ and Reynolds number of 500 .

Furthermore, the sensible heat part of total energy stored may be computed as

$$
Q_{\mathrm{sen}}^{\prime}(t)=\sum_{i=i_{1}}^{i_{2}} \pi(\rho . c)_{s}\left(T_{\mathrm{m}}-T_{\mathrm{w}, i}\right)\left[\left(r_{\mathrm{ice}, i}^{2}-r_{\mathrm{w}, i}^{2}\right)\left(1-\frac{1}{2 \ln r_{\mathrm{ice}, i} / r_{\mathrm{w}, i}}\right)-r_{\mathrm{ice}, i}^{2}\right] \frac{\delta x_{i}}{w+t}
$$


It can be seen from Equation (3) that the temperature distribution in solid ice is assumed to be a logarithmic function of radius. The total energy stored is calculated by adding latent heat part to sensible heat part.

\section{NUMERICAL MODEL}

A schematic representation of the physical model for an energy storage unit having finned tube is shown in Figure 2. The PCM fills the annular space, around the finned tube, of inner radius $r_{0}$ and outer radius $r_{\text {inf }}$, while heat transfer flows inside the tube. The tube wall has inside and outside radii of $r_{\mathrm{i}}$ and $r_{0}$. The outside wall of the energy storage unit is insulated. The thermophysical properties of the PCM, tube wall and heat transfer fluid are independent of temperature, but the properties of the PCM can be different in the solid and liquid phases. Initially, the system is at a temperature of $T_{\mathrm{i}}$ higher than $T_{\mathrm{m}}$. Suddenly; HTF having temperature $T_{\text {in }}$ lower than $T_{\mathrm{m}}$ flows in the finned tube and solidification occurs around the finned tube. In formulating a mathematical model to represent this physical system, the system is divided into following three subsections;

1. tube flow of heat transfer fluid,

2. the finned tube,

3. the region filled by the phase change material.

In addition, to reduce the number of parameters that have to be specified for the solutions, dimensionless variables and groups are first introduced as follows:

$$
\begin{aligned}
& R=\frac{r}{D}, \quad X=\frac{x}{D}, \quad \tau=\frac{\alpha_{\mathrm{f}} . t}{D^{2}}, \quad \theta=\frac{T-T_{\mathrm{m}}}{T_{\mathrm{m}}-T_{\mathrm{in}}}, \quad \delta \theta_{\mathrm{m}}=\frac{\delta T_{\mathrm{m}}}{\left(T_{\mathrm{m}}-T_{\mathrm{in}}\right)} \\
& \operatorname{Re}_{\mathrm{f}}=\frac{4 \dot{m}}{\pi D \mu_{\mathrm{f}}}, \quad \operatorname{Pr}_{\mathrm{f}}=\frac{\gamma_{\mathrm{f}}}{\alpha_{\mathrm{f}}}, \quad \operatorname{Pe}_{\mathrm{f}}=\operatorname{Re}_{\mathrm{f}} \operatorname{Pr}_{\mathrm{f}}, \quad \operatorname{Ste}=\frac{c_{p l} \cdot\left(T_{\mathrm{m}}-T_{\mathrm{in}}\right)}{\Delta H} \\
& C=\frac{C^{0}}{\rho_{\mathrm{l}} c_{\mathrm{l}}}, \quad S=\frac{\mathrm{S}^{0}}{\rho_{\mathrm{l}} c_{\mathrm{l}}\left(T_{\mathrm{m}}-T_{\mathrm{in}}\right)}, \quad K=\frac{k}{k_{\mathrm{l}}}
\end{aligned}
$$

Assuming that axial conduction is negligible and fully developed conditions exist at the tube inlet, the dimensionless energy equation of the heat transfer fluid can be expressed as

$$
\frac{\partial \theta_{\mathrm{b}}}{\partial \tau}=4 \mathrm{Nu}_{\mathrm{b}}\left(\theta_{\mathrm{w}}-\theta_{\mathrm{b}}\right)-\operatorname{Re}_{\mathrm{f}} \operatorname{Pr}_{\mathrm{f}} \frac{\partial \theta}{\partial X}
$$

The quasi-steady assumption is applied to convection heat transfer inside the tube. Transient convection is treated inside the tube as a series of steady state forced convection problems. For laminar flow, the local Nusselt number can be obtained by an analytical method with arbitrary varying temperature at the tube wall which is described by Kays and Crawford (1980), and Zhang and Faghri (1996b).

$$
\left(\mathrm{Nu}_{\mathrm{b}}\right)_{j}=\frac{\sum_{k=1}^{j} \Delta \theta_{k} \sum_{n=0}^{\infty} G_{n} \exp \left[-2 \lambda_{n}^{2} / \mathrm{Pe}_{\mathrm{f}}(X-(k-1) \Delta X)\right]}{2 \sum_{k=1}^{j} \Delta \theta_{k} \sum_{n=0}^{\infty} G_{n} / \lambda_{n}^{2} \exp \left[-2 \lambda_{n}^{2} / \mathrm{Pe}_{\mathrm{f}}(X-(k-1) \Delta X)\right]}
$$

where $\Delta \theta_{k}=\left(\theta_{R i}\right)_{k}-\left(\theta_{R i}\right)_{k-1}$ and $j=\operatorname{int}(X / \Delta X)+1$. 
The values of constant $G_{n}$ and eigenvalues $\lambda_{n}$ can be found in the studies of Kays and Crawford (1980). Furthermore, for turbulent flow, the local Nusselt number can be obtained by using empirical correlation described by Gnielinski (1976).

For finned pipe wall, the energy equation is well known as the two-dimensional heat conduction equation,

$$
\frac{\partial \theta}{\partial \tau}=\frac{\alpha_{1}}{\alpha_{\mathrm{f}}}\left[\frac{1}{R} \frac{\partial}{\partial R}\left(K R \frac{\partial \theta}{\partial R}\right)+\frac{\partial}{\partial X}\left(K \frac{\partial \theta}{\partial X}\right)\right]
$$

As the initial temperature of the system is considered to be the same or close to the phase change temperature, the natural convection effect around the tube and fins can be neglected. The heat conduction in the PCM is described by a temperature transforming method using a fixed grid numerical model (Cao and Faghri, 1990). This model assumes that solidification process occurs over a range of phase change temperature from $T_{\mathrm{m}}-\delta T_{\mathrm{m}}$ to $T_{\mathrm{m}}+\delta T_{\mathrm{m}}$, but it can also be successfully used to simulate solidification process occurring at a single temperature by taking a small range of phase change temperature, $2 \delta T_{\mathrm{m}}$. The dimensionless energy equation for the PCM is written as

$$
\frac{\partial(C \theta)}{\partial \tau}=\frac{\alpha_{1}}{\alpha_{\mathrm{f}}}\left(\frac{1}{R} \frac{\partial}{\partial R}\left(K R \frac{\partial \theta}{\partial R}\right)+\frac{\partial}{\partial X}\left(K \frac{\partial T}{\partial X}\right)\right)-\frac{\partial S}{\partial \tau}
$$

where

$$
\begin{gathered}
C=C(\theta)=\left\{\begin{array}{lll}
C_{\mathrm{sl}}, & \theta<-\delta \theta_{\mathrm{m}} & \text { solid phase } \\
\left(\frac{1}{2}\left(1+C_{\mathrm{sl}}\right)+\frac{1}{2 \operatorname{Ste} \delta \theta_{\mathrm{m}}}\right), & -\delta \theta_{\mathrm{m}} \leqslant \theta \leqslant \delta \theta_{\mathrm{m}} & \text { mushy phase } \\
1, & \theta>\delta \theta_{\mathrm{m}} & \text { liquid phase }
\end{array}\right. \\
S=S(\theta)=\left\{\begin{array}{lll}
C_{\mathrm{sl}} \delta \theta_{\mathrm{m}}, & \theta<-\delta \theta_{\mathrm{m}} & \text { solid phase } \\
\left(\frac{1}{2} \delta \theta_{\mathrm{m}}\left(1+C_{\mathrm{sl}}\right)+\frac{1}{2 \mathrm{Ste}}\right), & -\delta \theta_{\mathrm{m}} \leqslant \theta \leqslant \delta \theta_{\mathrm{m}} & \text { mushy phase } \\
C_{\mathrm{sl}} \delta \theta_{\mathrm{m}}+\frac{1}{\mathrm{Ste}}, & \theta>\delta \theta_{\mathrm{m}} & \text { liquid phase }
\end{array}\right. \\
K=K(\theta)=\left\{\begin{array}{lll}
K_{\mathrm{sl}}, & \theta<-\delta \theta_{\mathrm{m}} & \text { solid phase } \\
K_{\mathrm{sl}}+\left(1-K_{\mathrm{sl}}\right)\left(\theta+\delta \theta_{\mathrm{m}}\right) / 2 \delta \theta_{\mathrm{m}}, & -\delta \theta_{\mathrm{m}} \leqslant \theta \leqslant \delta \theta_{\mathrm{m}} & \text { mushy phase } \\
1, & \theta>\delta \theta_{\mathrm{m}} & \text { liquid phase }
\end{array}\right.
\end{gathered}
$$

The initial and boundary conditions are defined as follows:

Initial conditions: $\tau=0$

$$
0 \leqslant X \leqslant L / D, \quad 0 \leqslant R \leqslant R_{\text {inf }}, \quad \theta=\theta_{i}
$$

Boundary conditions: $\tau>0$

$$
X=0, \quad 0<R<0.5: \quad \theta=\theta_{\text {in }}=-1
$$




$$
\begin{gathered}
X=0, \quad 0.5<R<R_{\mathrm{inf}}: \quad \frac{\partial \theta}{\partial X}=0 \\
0 \leqslant X \leqslant L / D, \quad R=\left.R_{\mathrm{inf}} \quad \frac{\partial \theta}{\partial R}\right|_{R=R_{\mathrm{inf}}}=0 \\
X=L / D, \quad 0<R<R_{\mathrm{inf}}: \quad \frac{\partial \theta}{\partial X}=0
\end{gathered}
$$

Temperature distribution inside the solution domain can be calculated by solving the energy equations. The solution procedure used for solving this energy equation which has been defined by Equations (4)-(10) is the control volume approach described by Patankar (1980). Assuming the bulk temperature approach in the pipe flow, local Nusselt number is determined by using Equation (5) for laminar flow or by using empirical correlation for turbulent flow. However, thermal conductivity, $K$, is calculated by harmonic mean method at the control surface. Semi implicit solver (Lee, 1989), is used for solving the discretization equations of energy equations. Due to using this solver, the CPU time is reduced a great amount for a single iteration and this solver requires less storage than the other solvers.

Since energy equation occupied by PCM is a non-linear heat conduction equation, iterations are needed during each time step. For a given time step, convergence is declared at the $k+1$ th iteration when $\left|\theta_{i, j}^{k+1}-\theta_{i, j}^{k}\right| \leqslant 10^{-5}$. The grid size used for the solution was 168 (axial) $\times 114$ (radial) with a time step $\Delta \tau=0.001$ for finned tube type 1 . The total number of axial nodes increases with the number of fins. In addition, starting the fin-tip in PCM, non-uniform grid size is used with a successive ratio of 1.04 .

Furthermore, the overall energy balance is checked during the calculation process to verify the numerical results. At a time step, the change in the stored energy of the PCM and finned tube must be equal to the total energy supplied by the heat transfer fluid as follows,

$$
\int_{0}^{\tau} \frac{\pi}{4} \cdot \mathrm{Pe}_{\mathrm{f}} \cdot C_{\mathrm{f}} \cdot\left(\theta_{\mathrm{b}, \text { out }}+1\right) \mathrm{d} \tau=\int_{0}^{L} \int_{R_{i}}^{R_{\text {out }}} 2 \pi \cdot R \cdot\left(H-H_{i}\right) \mathrm{d} R \mathrm{~d} X
$$

where $H=C . T+S$ is total enthalpy at the control volume.

The left side of Equation (12) represents the thermal stored energy in the PCM and fins and the right side of the equation represents the thermal energy supplied by the heat transfer fluid. In calculations, the numerical deviation between two sides of Equation (12) is taken less than $2 \%$.

\section{RESULTS AND DISCUSSION}

Before presenting the numerical results for the thermal storage system, the mathematical model was checked with other numerical results in literature. Lacroix (1993) analysed the phase change problem of PCM around a finned tube and bare tube by using enthalpy method in terms of both radial and axial directions and has linked it to the convective heat transfer from the HTF. In Lacroix's numerical model, the local Nusselt number is calculated by Graetz solution. Also, the fins are assumed to be very thin and the effect of natural convection in the melt region is considered by employing an effective thermal conductivity. This effect is also included in the present method to make the comparison more meaningful. But, it is not used in the main analysis. Figure 4 shows the comparison of the molten volume fraction (MVF) obtained by 


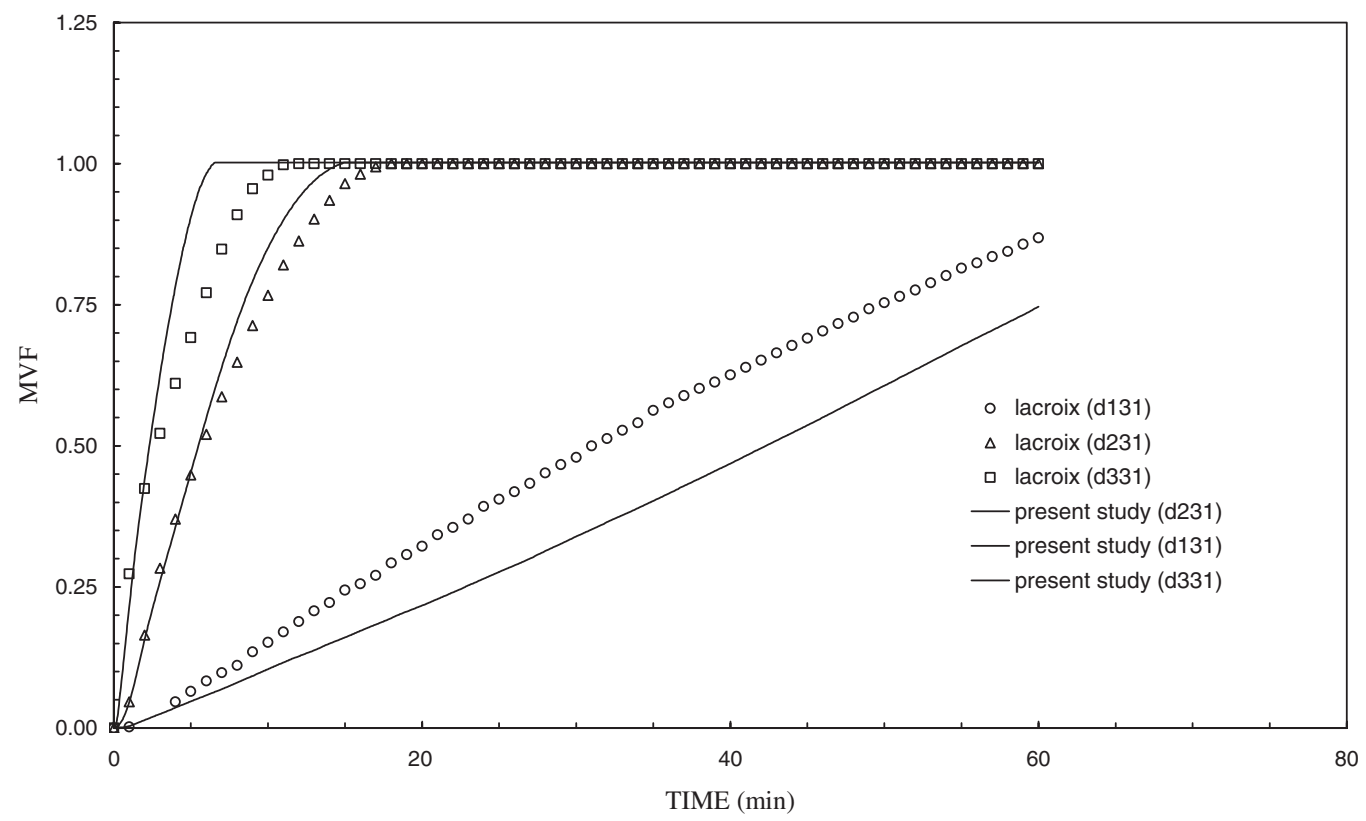

Figure 4. Comparison of the present numerical results of MVF with Lacroix (1993).

present method and Lacroix's method. It can be seen that the agreement between the two results is generally good. The reason of small difference between the results may be using the difference approach in the calculation of local Nusselt number in the tube and neglecting the thermal resistance inside the tube surface in Lacroix's.

Figure 5 displays the comparison between the present numerical model and the experimental results where the position of the solidification front on fin type 1 at the different times. In this comparison, the inlet temperature of the HTF and Re number is taken to be $-15^{\circ} \mathrm{C}, 500$, respectively. It is obvious from this figure that solidification front increases as time go by. In addition, Figure 6 shows the comparison between numerical and experimental results of total thermal energy stored for fin type 3 and different Reynolds numbers. The amount of stored energy in experimental work seems lower than the numerical one for low Reynolds number. But when the Reynolds number is increased, the amount in experimental work becomes larger than the numerical one. This is expected due to the turbulence creating factors in the experimental setup such as fittings, elbows, etc. for higher flow rates.

Figure 7 shows the total thermal energy stored as a function of time for different fin types (fin spaces and fin radius). The stored energy increases increasing fin radius and decreasing fin space. In addition, it can be seen from this figure that Reynolds number has a dominant effect on the stored energy than fin parameters. If the Reynolds number is increased five times for the fins having same dimensional parameters, the amount of stored energy is doubled, approximately.

The effect of fin type on heat transfer rate is given on Figure 8. These results show that the increase in Reynolds number and fin area increase the energy storage rate, as expected. This rate also increases with the decreasing fin spacing.

Figure 9 shows the effect of the fin radius and Reynolds number on the position of the solidification fronts. As expected, the solidification fronts increase as fin radius and Reynolds 


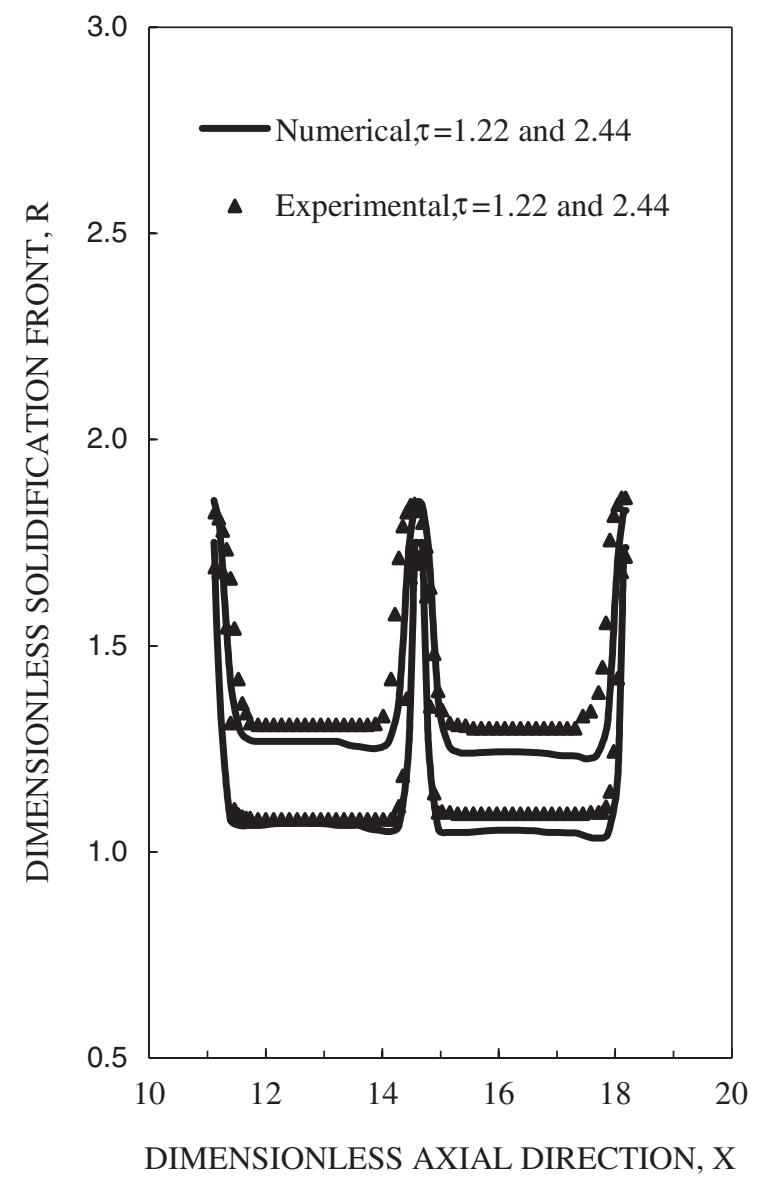

Figure 5. Comparison of numerical and experimental results on the solidification fronts.

number increases. The curves indicate that increase in fin radius results with an increase in solidification radius.

Furthermore, the effect of Reynolds number on the total thermal energy stored is shown in Figure 10. The total amount of stored energy is dramatically increased after the transition from laminar to turbulent flow is passed. But, increase rate of the stored energy decreases as Reynolds number increases, especially beyond the Reynolds number of 5000 .

The effect of Stefan number on the solidification fronts which depends on the difference between the fluid inlet and melting temperatures is shown in Figure 11. It can be seen that the effect of Stefan number on the solidification front at the axial position is very significant.

As dimensionless total energy stored and Stefan number is included $\left(T_{\mathrm{m}}-T_{\mathrm{in}}\right)$, new dimensionless total energy stored has to be defined to show the effect of Stefan number on total energy stored. The new dimensionless energy stored is determined as

$$
Q^{*}=Q \text { Ste }=\frac{Q^{0}}{D^{3} \rho_{l} \cdot \Delta H}
$$




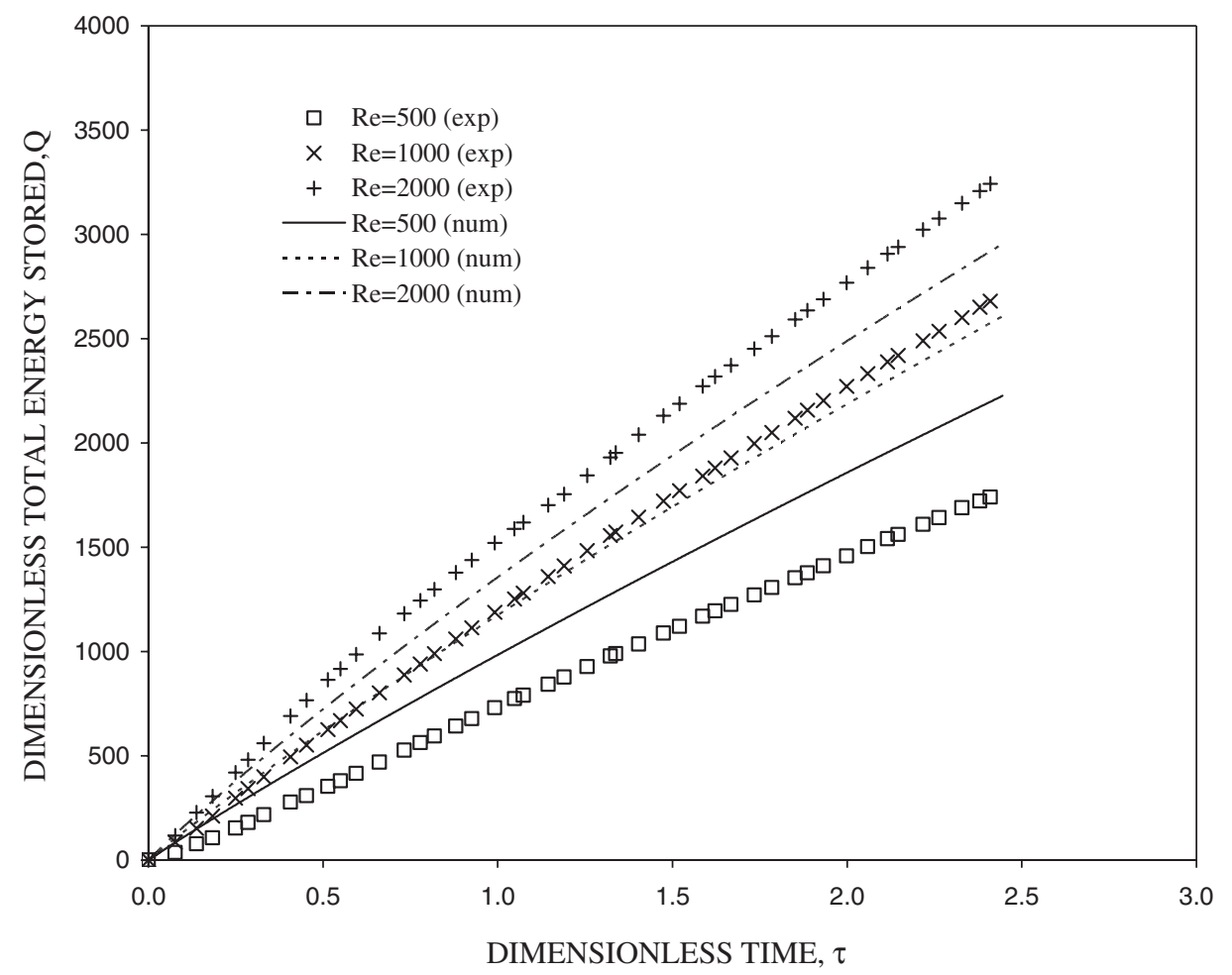

Figure 6. Comparison of numerical and experimental results on total stored energy.

Figure 12 shows the effect of Stefan number on the total thermal energy stored for tube type 3. As the effect of Reynolds number, the energy storage process can be accelerated by increasing the Stefan number. The total energy stored for the different fin types and flow parameters are summarized in Table II. It can be seen from this table that the effects of Reynolds number and Stefan number on the total energy stored are excessive than fin parameters.

\section{CONCLUSION}

A numerical model has been developed to investigate the energy storage system having the configuration of a radially finned tube situated in a container which has insulated outer walls. The flow Reynolds number Re, the Stefan number Ste, the fin diameter $\mathrm{D}_{\mathrm{f}}$, and fin spacing are determined affecting the solidification around finned tube. In the numerical analysis, Reynolds number is taken in various values as $500,1000,2000,3000,5000$, and 7000 . The dimensionless fin diameter is in the range of 2.7 and 3.2 and the fin spacing varied from 1.375 and 2 .

An experimental apparatus has been designed and built for providing a basis to show how well the numerical model predicts the thermal behaviour of the energy storage unit equipped with a finned tube. The stored total energy evaluated by the numerical method agrees reasonably with the experimental data. 


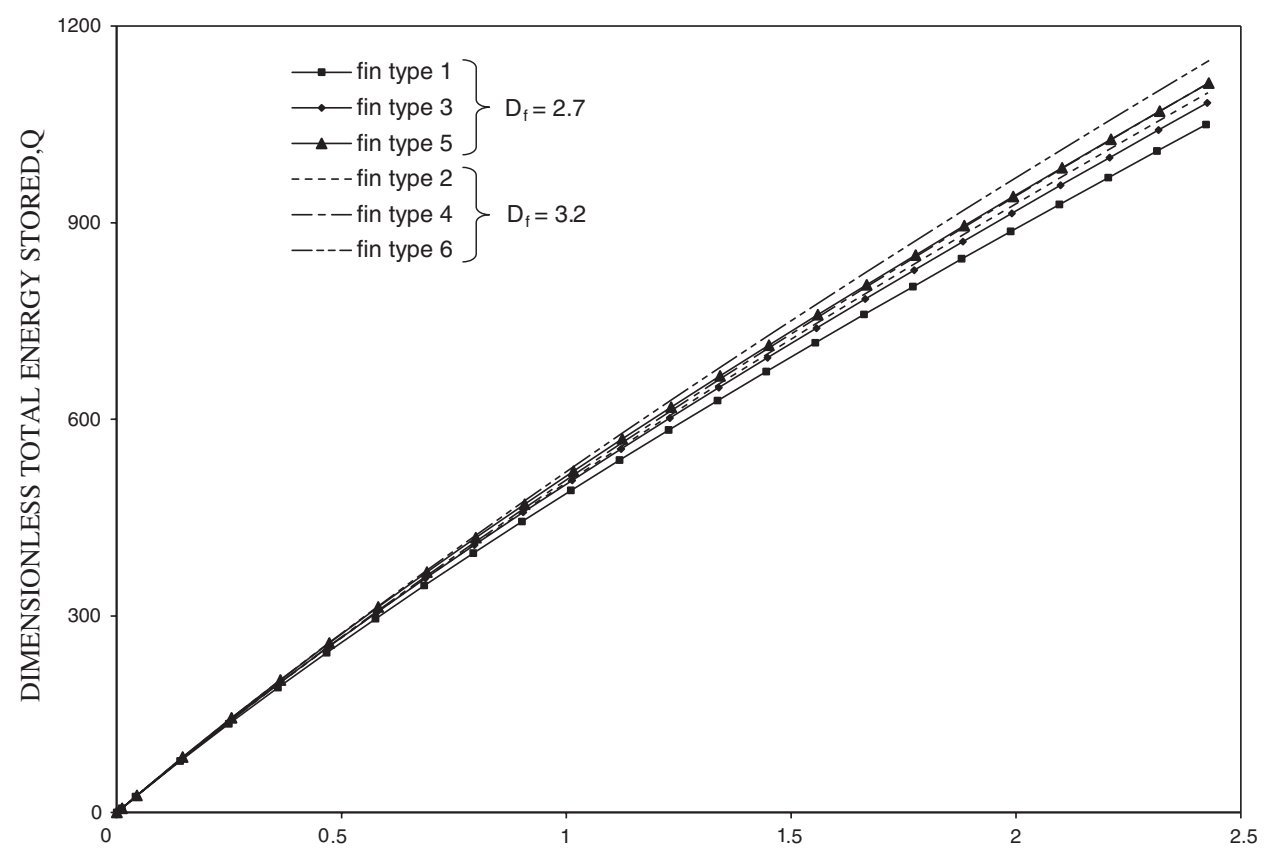

(a)

DIMENSIONLESS TIME, $\tau$

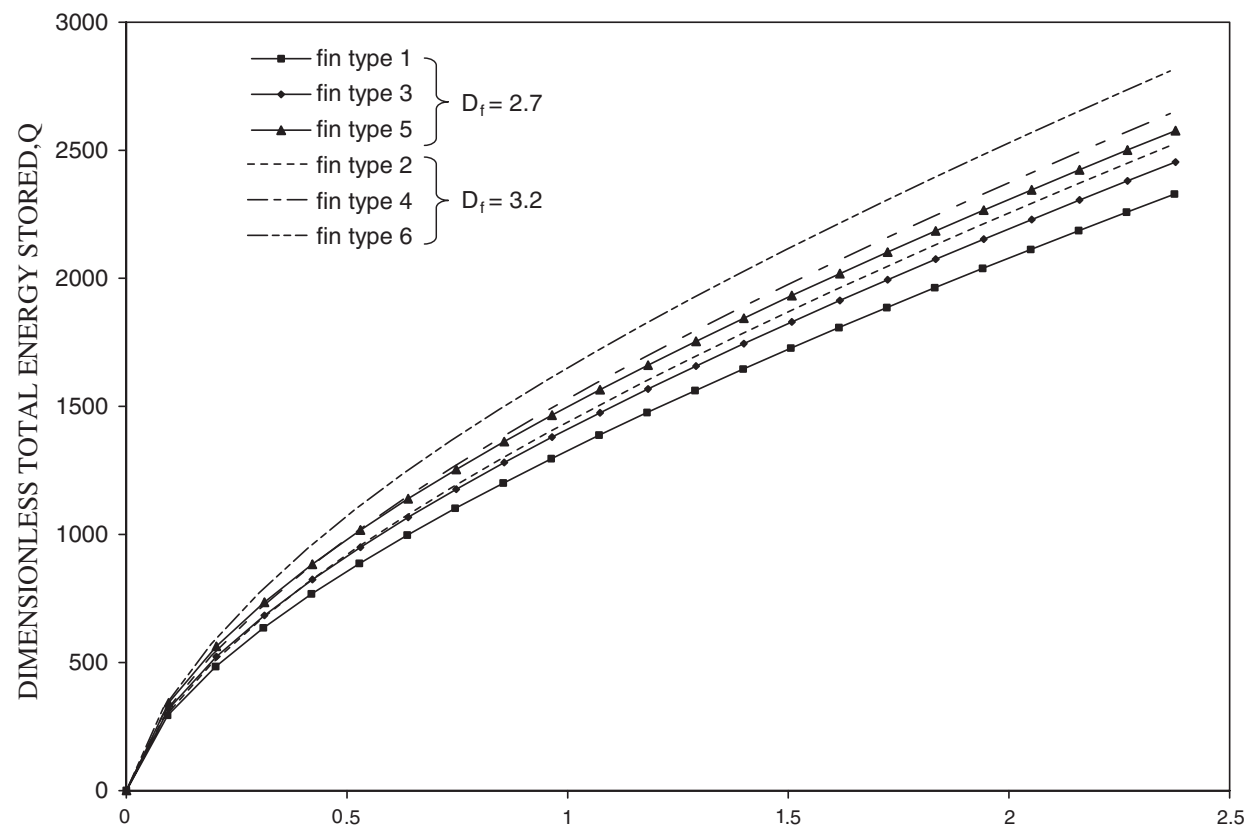

(b)

DIMENSIONLESS TIME, $\tau$

Figure 7. Effect of fin type on total stored energy. (a) $\operatorname{Re}=1000$; and (b) $\operatorname{Re}=5000$. 

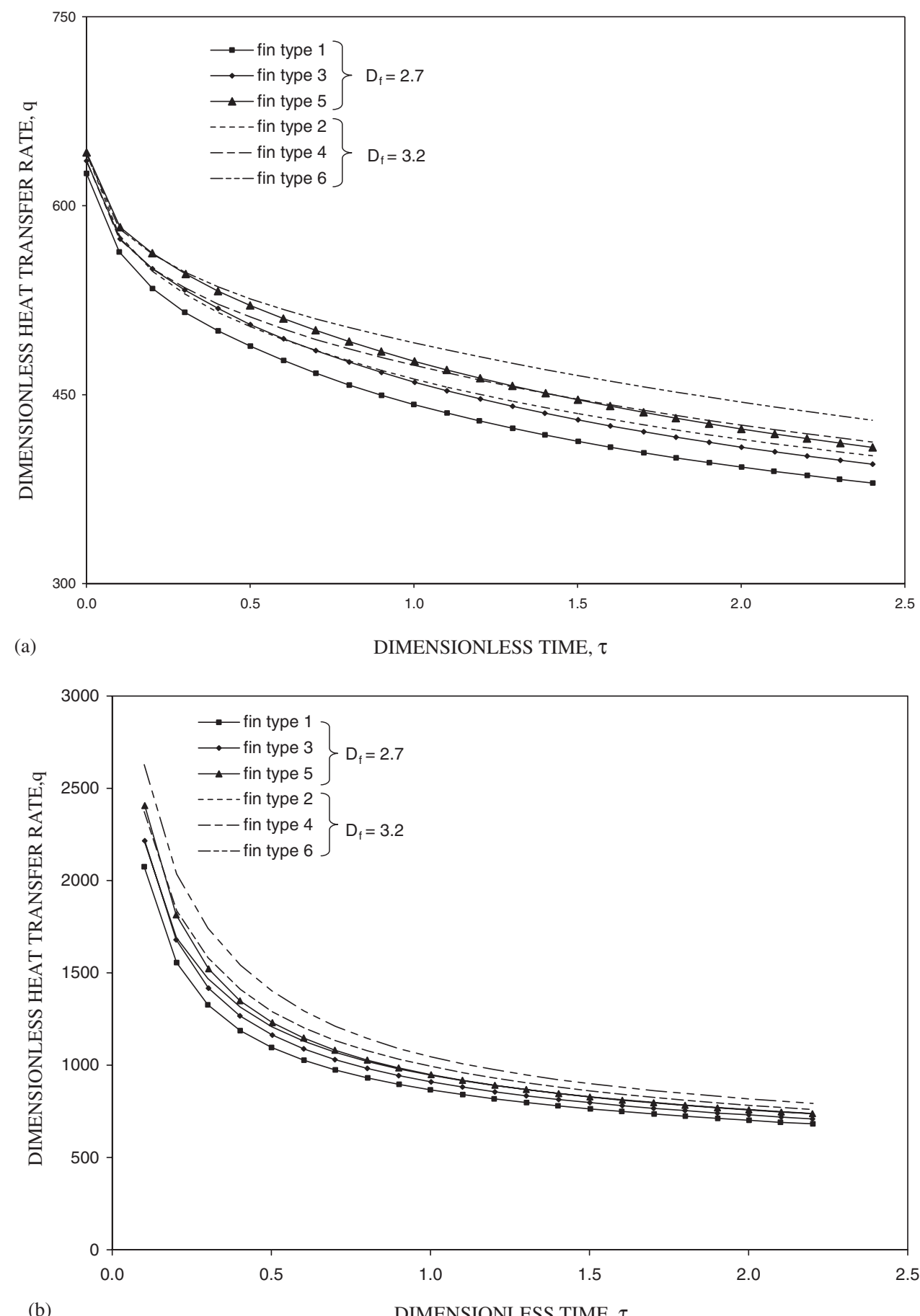

Figure 8. Effect of fin type on heat transfer rate (a) $\operatorname{Re}=1000$; and (b) $R e=5000$. 


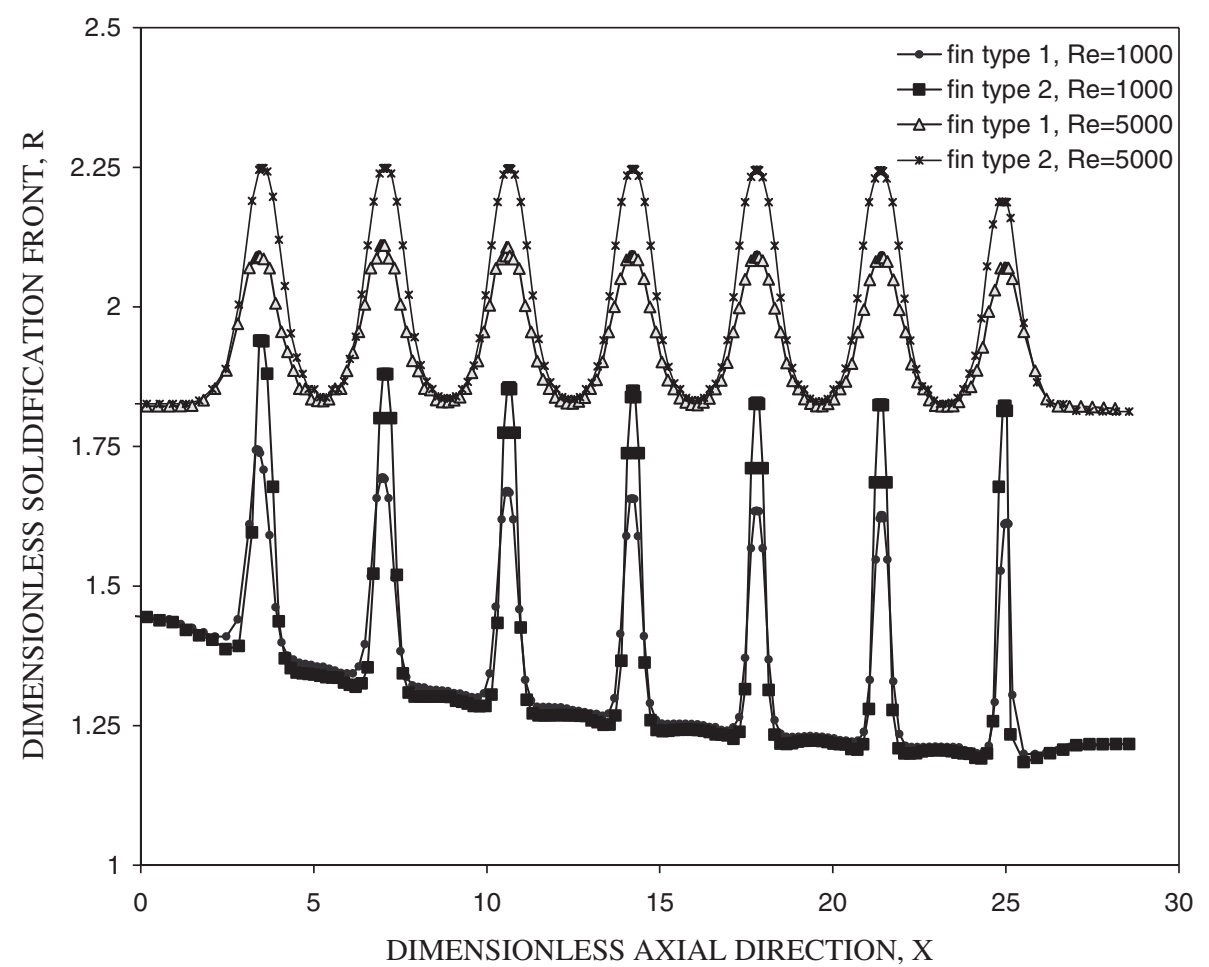

Figure 9. Effect of fin diameter on solidification fronts.

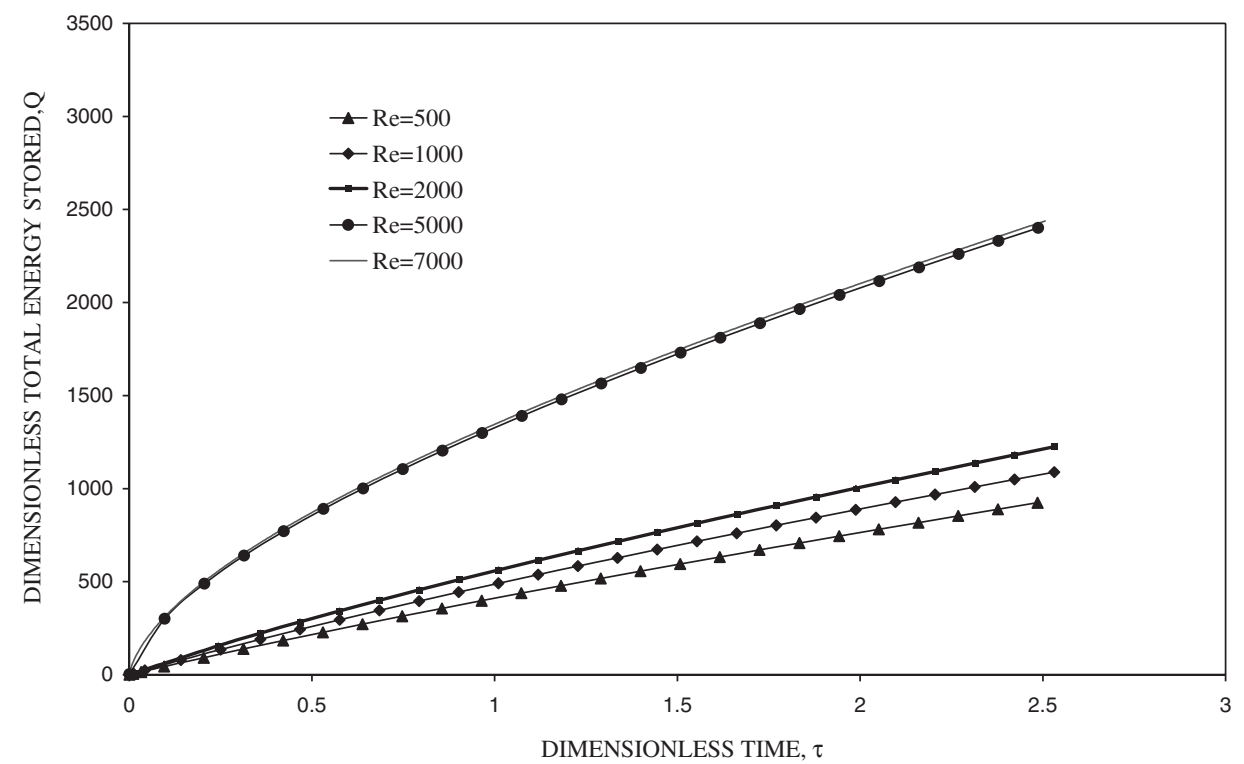

Figure 10. Effect of Reynolds number on total stored energy. 


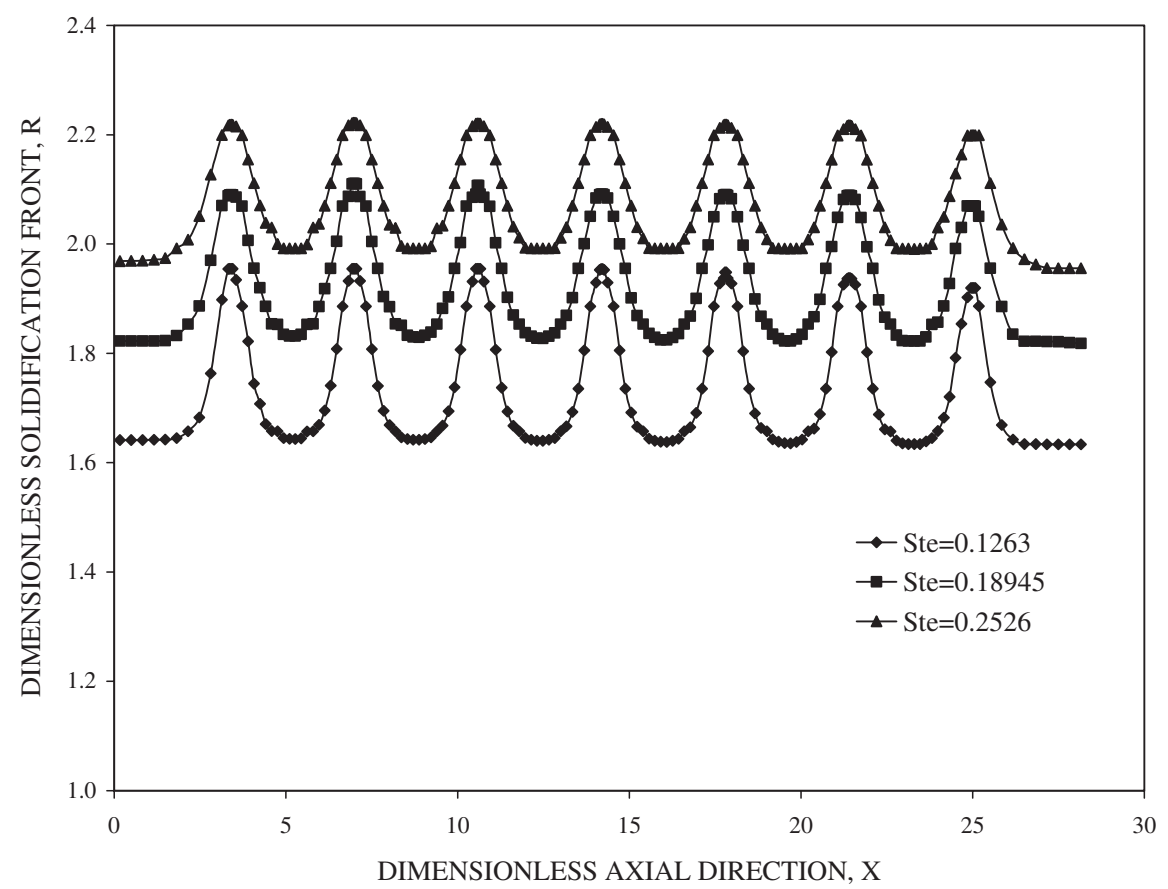

Figure 11. Effect of Stefan number on solidification fronts.

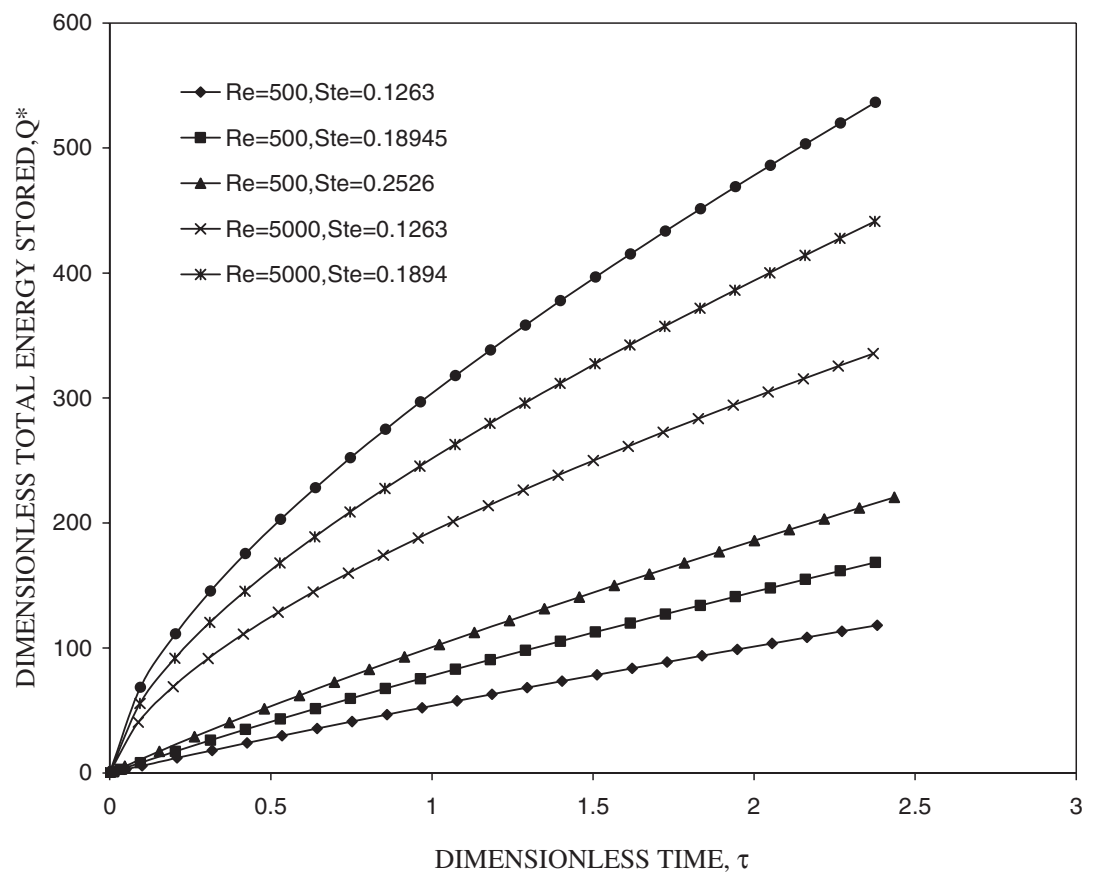

Figure 12. Effect of Stefan number on total stored energy. 
Table II. Total stored energy $Q^{*}$ for different flow conditions at the dimensionless time of 1.2 and 2.4.

\begin{tabular}{lrrrrrrr}
\hline Flow conditions & Fin type 1 & Fin type 2 & Fin type 3 & Fin type 4 & Fin type 5 & Fin type 6 & Fin type 7 \\
\hline $\mathrm{Re}=500$, & 64.77 & - & 66.33 & - & 67.82 & - & - \\
$\mathrm{Ste}=0.1263$ & 121.02 & - & 124.29 & - & 127.21 & - & - \\
$\mathrm{Re}=500$, & 93.37 & 96.34 & 95.90 & 97.06 & 98.06 & 99.55 & 92.01 \\
$\mathrm{Ste}=0.18945$ & 172.67 & 179.56 & 177.50 & 181.40 & 181.76 & 186.25 & 162.11 \\
$\mathrm{Re}=500$, & 120.67 & - & 123.65 & - & 126.45 & - & - \\
$\mathrm{Ste}=0.2526$ & 221.27 & - & 227.44 & - & 232.70 & - & - \\
$\mathrm{Re}=1000$, & 109.98 & 114.14 & 113.37 & 115.28 & 116.28 & 118.37 & 103.35 \\
$\mathrm{Ste}=0.18945$ & 200.00 & 209.34 & 206.48 & 212.17 & 212.09 & 218.53 & 188.11 \\
$\mathrm{Re}=2000$, & 125.70 & 130.87 & 129.85 & 132.47 & 133.18 & 138.51 & 124.22 \\
$\mathrm{Ste}=0.18945$ & 225.05 & 236.62 & 232.92 & 240.37 & 239.37 & 253.73 & 208.21 \\
$\mathrm{Re}=5000$, & 219.35 & - & 233.40 & - & 248.56 & - & - \\
$\mathrm{Ste}=0.1263$ & 342.37 & - & 361.52 & - & 383.52 & - & - \\
$\mathrm{Re}=5000$, & 286.03 & 310.13 & 303.46 & 328.89 & 321.35 & 353.59 & 260.74 \\
$\mathrm{Ste}=0.18945$ & 449.09 & 487.46 & 473.40 & 511.52 & 496.97 & 543.40 & 409.37 \\
$\mathrm{Re}=5000$, & 345.56 & - & 359.96 & - & 385.32 & - & - \\
$\mathrm{Ste}=0.2526$ & 546.83 & - & 564.06 & - & 599.80 & - & - \\
$\mathrm{Re}=7000$, & 289.48 & 314.58 & - & 333.74 & - & 359.06 & - \\
$\mathrm{Ste}=0.18945$ & 453.73 & 493.06 & - & 571.20 & - & 549.97 & - \\
\hline
\end{tabular}

The effect of all the parameters on the stored energy is given in Table II. The stored energy increases with increasing fin radius and decreasing fin space. In addition, the stored energy increases with increasing Reynolds number and Stefan number. After a certain value of Reynolds number which is about 5000, the total amount of stored energy does not change too much.

\section{NOMENCLATURE}

$c, c_{\mathrm{p}}$
$C^{0}$
$C$
$C_{\mathrm{sl}}$
$D$
$H$
$k$
$K$
$K_{\mathrm{sl}}$
$L$
$\mathrm{MVF}$
$\mathrm{Pe}_{\mathrm{f}}$
$\mathrm{Pr}_{\mathrm{f}}$
$q$
$Q^{0}$
$Q$
$r$
$R$

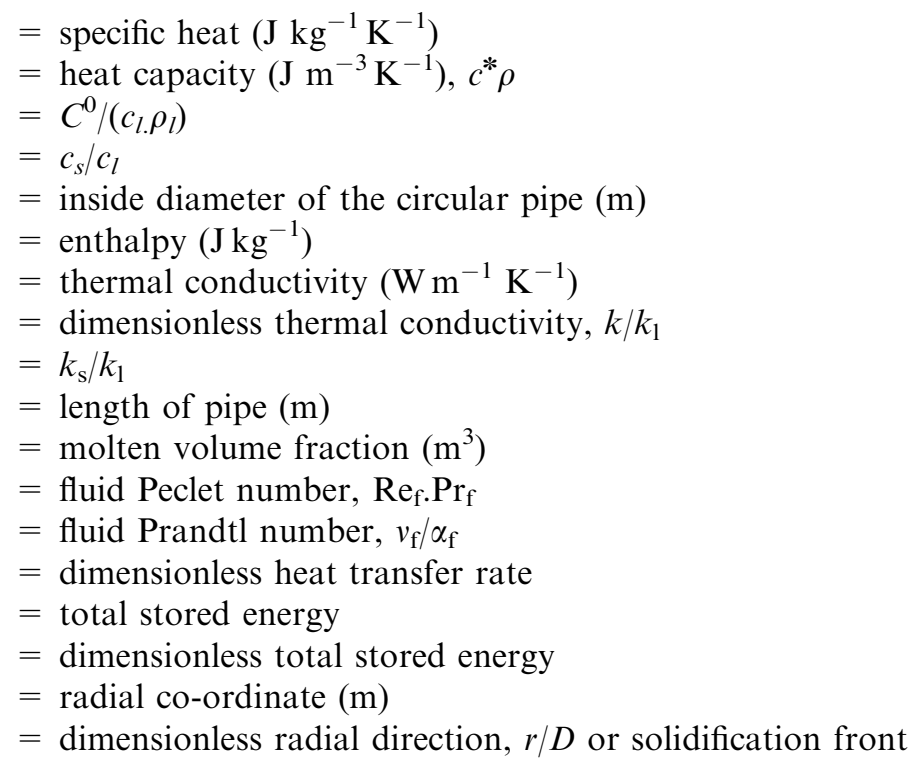




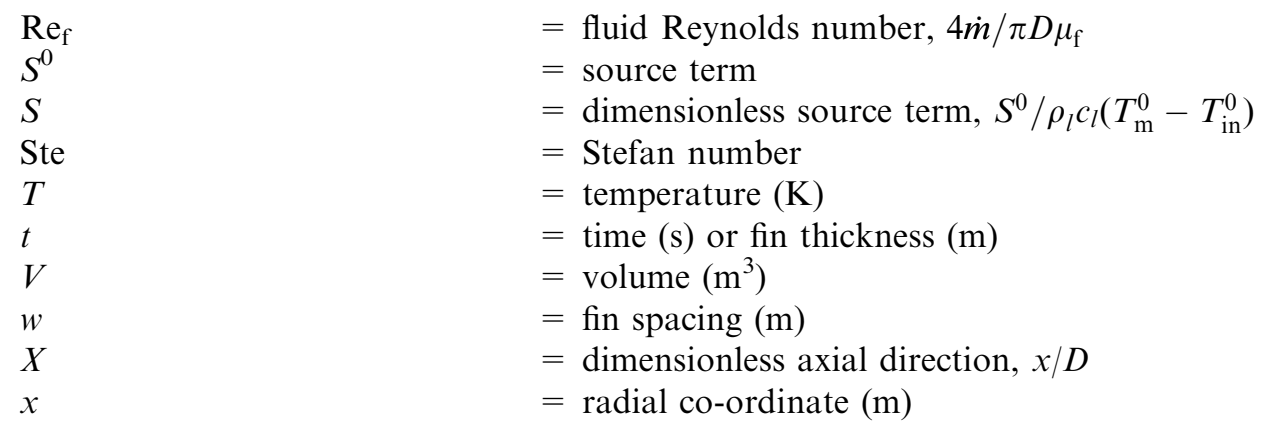

\section{Greek symbols}

$\alpha$

$2 \delta T_{\mathrm{m}}$

$\delta \theta_{\mathrm{m}}$

$\Delta H$

$\theta$

$v$

$\mu$

$\rho$

$\tau$

\section{Subscripts}

f
i
in
inf
1
m
o
s
W

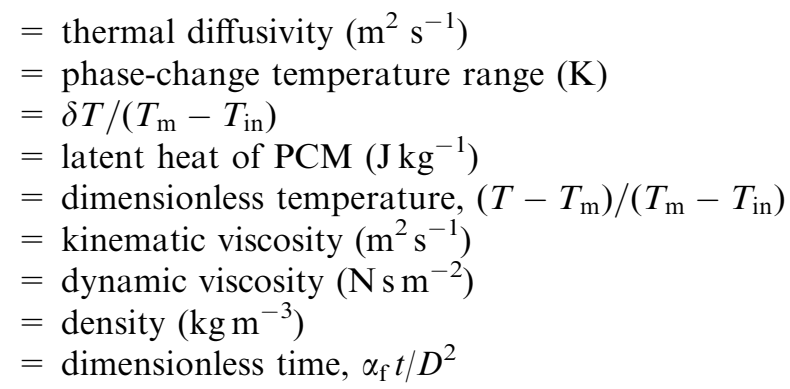

$=$ transfer fluid, or fin

$=$ initial condition, or inside radius of the pipe

$=$ inlet

$=$ outside of the thermal storage tank

$=$ liquid $\mathrm{PCM}$

$=$ mushy phase

$=$ outside radius of the pipe

$=$ solid PCM

$=$ container wall or surface

\section{ACKNOWLEDGEMENTS}

This work was supported by Natural Science Foundation of Dokuz Eylül Universities through AIF Grant No: 02.KB.FEN.028.

\section{REFERENCES}

Bathelt AG, Viskanta R. 1981. Heat transfer and interface motion during melting and solidification around a finned horizontal sink/source. Journal of Heat Transfer 103:720-726.

Bellecci C, Conti M. 1993. Phase change thermal storage: transient behaviour analysis of a solar receiver/ storage module using the enthalpy method. International Journal of Heat Mass Transfer 36:2157-2163. 
Cao Y, Faghri A. 1990. A numerical analysis of phase-change problem including natural convection. Journal of Heat Transfer (ASME) 112(3):812-816.

Cao Y, Faghri A. 1991a. A PCM/forced convection conjugate transient analysis of energy storage systems with annular and countercurrent flows. Journal of Heat Transfer ASME 113:37-42.

Cao Y, Faghri A. 1991b. Performance characteristics of a thermal energy storage module: a transient PCM/forced convection conjugate analysis. International Journal of Heat Mass Transfer 34:93-101.

Cao Y, Faghri A. 1992. A study of thermal energy storage system with conjugate turbulent forced convection. Journal of Heat Transfer ASME 114:1019-1027.

Dinçer I, Rosen MA. 2002. Thermal Energy Storage Systems and Applications. Wiley: London.

Eckert ERG, Goldstein RJ, Ibele WE, Patankar SV. 1997. Heat transfer-a review of 1994 literature. International Journal of Heat Mass Transfer 40:3729-3804.

Erek A. 1999. Phase change around finned horizontal cylinder: a conjugate problem. Ph.D. Thesis, Graduate School of Natural and Applied Sciences of Dokuz Eylul University, İzmir.

Gnielinski V. 1976. New equations for heat and mass transfer in turbulent pipe and channel flow. International Chemical Engineering 16:359-368.

Ismail KAR, Alves CLF. 1986. Analysis of the shell-and-tube PCM storage system. Proceedings of the 8th International Heat Transfer Conference, 1781-1786.

Ismail KAR, Henriquuez JR, Moura LFM, Ganzarolli MM. 2000. Ice formation around isothermal radial finned tubes. Energy Conversion \& Management 41:585-605.

Kays WM, Crawford ME. 1980. Convective Heat and Mass Transfer. McGraw-Hill: New York.

Lacroix M. 1993. Study of the heat transfer behaviour of a latent heat thermal energy storage unit with a finned tube. International Journal of Heat Mass Transfer 36:2083-2092.

Lee SL. 1989. A strongly implicit solver for two-dimensional elliptic differential equations. Numerical Heat Transfer (B) 16:161-178.

Padmanabhan PV, Khrishna MV. 1989. Outward phase change in a cylindrical annulus with axial fins on the inner tube, International Journal of Heat Mass Transfer 29:1855-1868.

Patankar SV. 1980. Numerical Heat Transfer and Fluid Flow. McGraw-Hill: New York.

Saito A. 2002. Recent advances in research on cold thermal energy storage. International Journal of Refrigeration $\mathbf{2 5}$ : $177-189$.

Sasaguchi K, Sakamoto Y. 1989. Effects of natural convection on melting of a phase change material around a finned tube. Transactions JSME 55(513):1418-1425.

Sparrow EM, Larson ED, Ramsey JM. 1981. Freezing on a finned tube for either conduction-controlled or natural convection-controlled heat transfer. International Journal of Heat Mass Transfer 24:273-284.

Zalba B, Marin JM, Cabeza LF, Mehling H. 2003. Review on thermal energy storage with phase change: materials, heat transfer analysis and applications. Applied Thermal Engineering 23:251-283.

Zhang Y, Faghri A. 1996a. Analytical solution of thermal energy storage system with conjugate laminar forced convection. International Journal of Heat Mass Transfer 39:717-724.

Zhang Y, Faghri A. 1996b. Heat transfer enhancement in latent heat thermal energy storage system by using the internally finned tube. International Journal of Heat Mass Transfer 39:3165-3173. 